\title{
Growth differentiation factor 15 mediates epithelial mesenchymal transition and invasion of breast cancers through IGF-1R-FoxM1 signaling
}

This article has been corrected. Correction in: Oncotarget. 2020; 11:4074-4075.

\author{
Bridgette F. Peake ${ }^{1,6, *}$, Siobhan M. Eze ${ }^{2, *}$, Lily Yang ${ }^{5,6}$, Robert C. Castellino ${ }^{3,6}$ and \\ Rita Nahta ${ }^{1,2,4,6}$ \\ ${ }^{1}$ Molecular \& Systems Pharmacology PhD Program, Graduate Division of Biological and Biomedical Sciences, Emory University, \\ Atlanta, GA, USA \\ ${ }^{2}$ Department of Pharmacology, School of Medicine, Emory University, Atlanta, GA, USA \\ ${ }^{3}$ Department of Pediatrics, School of Medicine, Emory University, Aflac Cancer \& Blood Disorders Center, Children's Healthcare \\ of Atlanta, Atlanta, GA, USA \\ ${ }^{4}$ Department of Hematology \& Medical Oncology, School of Medicine, Emory University, Atlanta, GA, USA \\ ${ }^{5}$ Department of Surgery, School of Medicine, Emory University, Atlanta, GA, USA \\ ${ }^{6}$ Winship Cancer Institute, Emory University, Atlanta, GA, USA \\ *These authors have contributed equally to this work \\ Correspondence to: Rita Nahta, email: RNAHTA@EMORY.EDU \\ Keywords: breast cancer, signaling, invasion \\ Received: April 26, $2017 \quad$ Accepted: September 15, $2017 \quad$ Published: October 10, 2017 \\ Copyright: Peake et al. This is an open-access article distributed under the terms of the Creative Commons Attribution License 3.0 \\ (CC BY 3.0), which permits unrestricted use, distribution, and reproduction in any medium, provided the original author and source \\ are credited.
}

\section{ABSTRACT}

Expression of the inflammatory cytokine growth differentiation factor 15 (GDF15) is significantly elevated in many tumor types in association with epithelial mesenchymal transition (EMT), drug resistance, and progressive disease. However, few studies have examined GDF15 expression, signaling, or function in breast cancer. In the current study, we demonstrate that GDF15 is associated with high tumor grade, ER-negativity, and HER2 overexpression in patients with breast cancer. Stable overexpression of GDF15 upregulates expression of mesenchymal markers and transcription factors, including FoxM1, and increases cellular invasion. GDF15 stable clones and breast cancer cells stimulated with recombinant human GDF15 (rhGDF15) demonstrate activation of insulinlike growth factor-1 receptor (IGF-1R), EMT, and invasion. Pharmacologic inhibition of IGF-1R reduces GDF15-mediated EMT and invasion in stable clones, and FoxM1 knockdown rescues invasion and EMT in GDF15 stable clones and rhGDF15-stimulated cells. These data suggest that IGF-1R-FoxM1 signaling is a potential mechanism through which GDF15 drives EMT and invasion of breast cancers. Further, GDF15 knockdown significantly inhibits invasion of HER2-overexpressing and triple-negative breast cancer cells, supporting further preclinical investigation of GDF15-targeted therapies.

\section{INTRODUCTION}

Growth differentiation factor 15 (GDF15; also referred to as macrophage inhibitory cytokine-1, MIC-1, and nonsteroidal anti-inflammatory drug activated gene1, NAG-1) is a stress-induced inflammatory cytokine $[1,2]$. Under normal physiological conditions, GDF15 is expressed abundantly only in the placenta. However, stressors, such as inflammation and injury, induce GDF15 expression in epithelial cells, fibroblasts, and macrophages. In addition, many pathologic conditions, including insulin resistance, diabetes, cardiovascular disease, impaired cognitive ability, and malignancies, are associated with elevated levels of circulating GDF15 [3-5]. Patients with advanced-stage cancers, including breast, express high levels of GDF15 in tumor tissues and/or sera [6-10]. 
Table 1: Correlations between GDF15 IHC score and clinical characteristics in patients with breast cancer

\begin{tabular}{|c|c|c|c|c|}
\hline \multirow[t]{2}{*}{ Characteristic, n (\%) } & \multirow[t]{2}{*}{$\mathrm{N}=592$} & \multicolumn{2}{|c|}{ GDF15 IHC score } & \multirow[t]{2}{*}{ P value } \\
\hline & & $\begin{array}{c}0 \\
(n=204)\end{array}$ & $\begin{array}{c}1+ \\
(n=388)\end{array}$ & \\
\hline Age (years) & & & & 0.7 \\
\hline$<50$ & $147(24.8)$ & 48 (32.7) & 99 (67.3) & \\
\hline$\geq 50$ & $445(75.2)$ & $156(35.1)$ & $289(64.9)$ & \\
\hline Grade & & & & 0.002 \\
\hline $1-2$ & $402(67.9)$ & $156(38.8)$ & $246(61.2)$ & \\
\hline 3 & $190(32.1)$ & $48(25.3)$ & $142(74.7)$ & \\
\hline Lymph node (\#) & & & & 0.3 \\
\hline$\leq 3$ & $515(87.0)$ & $173(33.6)$ & $342(66.4)$ & \\
\hline$>3$ & $77(13.0)$ & $31(40.3)$ & $46(59.7)$ & \\
\hline ER & & & & 0.03 \\
\hline Negative & $192(32.4)$ & $54(28.1)$ & $138(71.9)$ & \\
\hline Positive & $400(67.6)$ & $150(37.5)$ & $250(62.5)$ & \\
\hline HER2 & & & & 0.03 \\
\hline Negative & $517(87.3)$ & $187(36.2)$ & $330(63.8)$ & \\
\hline Positive & 75 (12.7) & $17(22.7)$ & $58(77.3)$ & \\
\hline
\end{tabular}

Abbreviations: ER, estrogen receptor; GDF15, growth differentiation factor 15; HER2, human epidermal growth factor receptor 2; IHC, immunohistochemistry

GDF15 shares structural features with members of the transforming growth factor-beta (TGF-beta) superfamily [1], and was recently demonstrated to bind with high affinity to the orphan receptor glial-derived neurotrophic factor-family receptor-alpha-like (GFRAL) [11-13]. GDF15 overexpression stimulates PI3K/Akt/ mTOR and MEK/ERK signaling [14-17], and promotes epithelial to mesenchymal transition (EMT) in colorectal and ovarian cancer cells $[18,19]$. GDF 15 promotes the acquisition of cancer stem cell-like properties in breast cancers [16], and confers resistance to HER2-targeted therapy in breast cancer [14]. In the current study, we demonstrate that GDF15 promotes EMT and invasiveness of breast cancers through insulin-like growth factor-1 receptor (IGF-1R) signaling and transcription factor FoxM1 upregulation.

\section{RESULTS}

\section{GDF15 expression correlates with ER-negative and HER2-positive status in patients with breast cancer}

GDF15 expression, as assessed by IHC (Figure 1), was correlated with baseline clinical characteristics in a cohort $(\mathrm{N}=592)$ of patients with breast cancer (Table 1).
The majority of patients were older than 50 years $(75 \%)$ and had low-grade tumors (68\%). GDF15 expression (staining score $\geq 1$ ) was observed in approximately twothirds (65\%) of patients. GDF15-positive scoring correlated with high tumor grade $(\mathrm{P}=0.002)$, as approximately $75 \%$ of patients with high-grade tumors displayed a GDF15 score of $1+$. Most (87\%) patients in the cohort had fewer than four lymph node metastases. Stratification of patients based on $\leq 3$ lymph node metastases versus $>3$ lymph node metastases did not show significant correlation with GDF15 staining. The molecular subtypes of breast cancers represented in the cohort were consistent with published literature $[6,20]$, with $68 \%$ estrogen receptor (ER)-positive tumors and $13 \%$ human epidermal growth factor receptor 2 (HER2)-positive. A majority of patients in each subtype expressed GDF15, with a statistically higher percentage of ER-negative and HER2-positive tumors exhibiting GDF15positivity ( $\mathrm{P}=0.03$ for each).

\section{GDF15 overexpression alters cell cycle profiles and induces EMT in breast cancer}

BT474 and JIMT1 breast cancer cells express low levels of GDF15, whereas MDA-MB-231 (MDA231) breast cancer cells demonstrate high endogenous expression of GDF15 (Figure 2A). Stable 
GDF15 Score 0

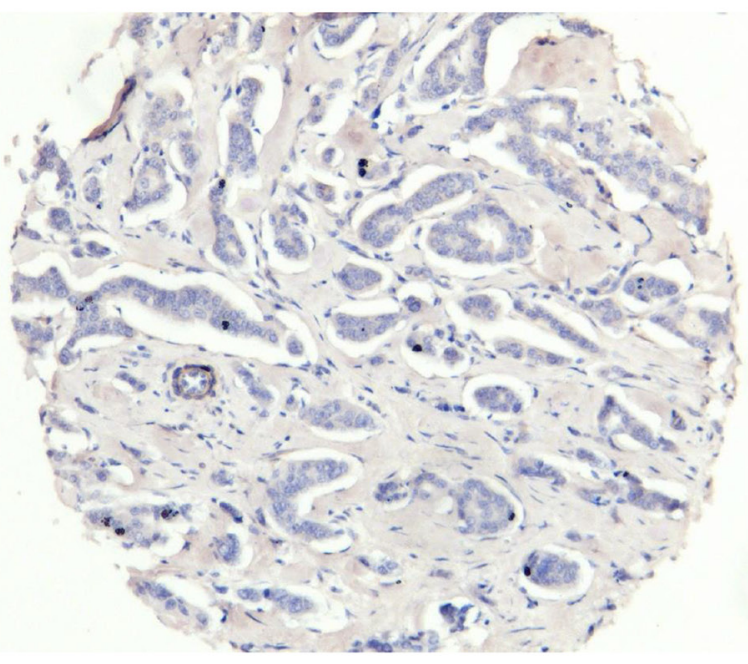

GDF15 Score 3

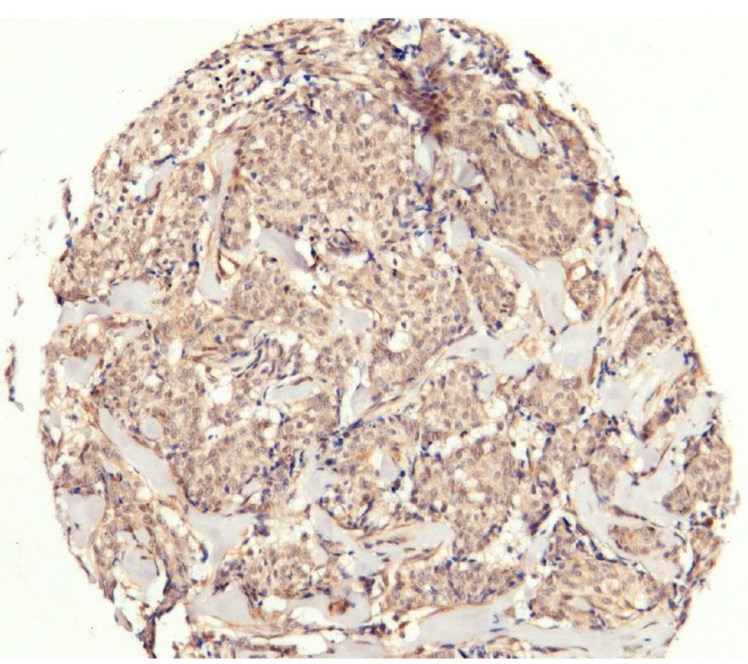

Figure 1: Representative GDF15 immunohistochemical (IHC) staining. Representative images of breast tumor tissues scored as 0 (left) or 3 (right) for GDF15 IHC staining.
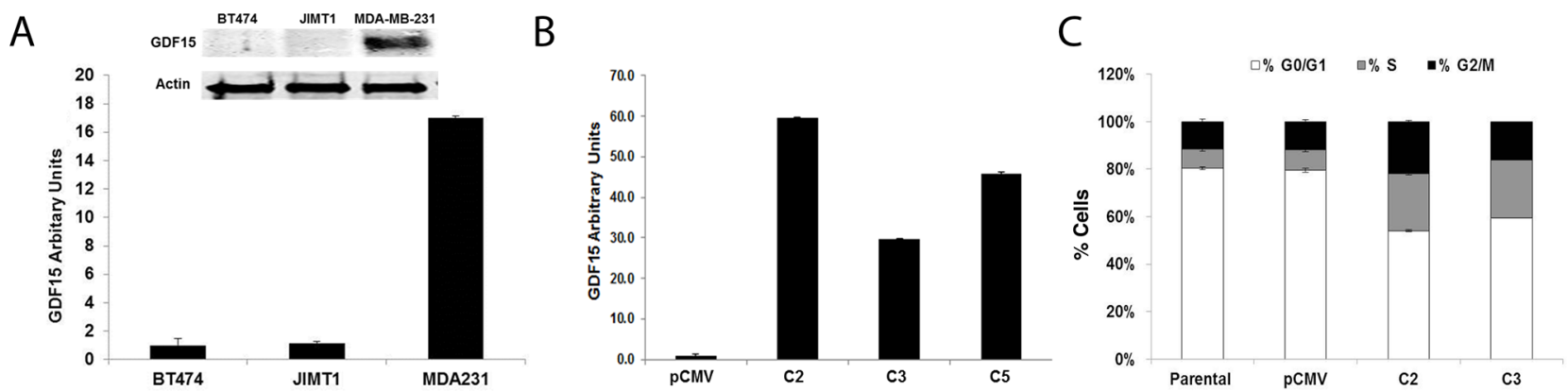

D

BT474
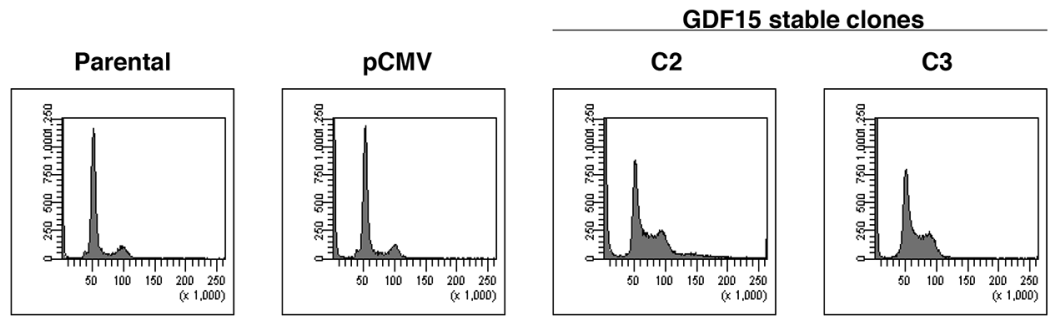

Figure 2: GDF15 overexpression alters breast cancer cell cycle profile. (A) Western blotting (above) and real-time PCR (graph) for GDF15 in BT474, JIMT1 and MDA-MB-231 (MDA231) breast cancer cell lines. PCR values reflect fold change in GDF15 transcript normalized to RPLPO housekeeping gene. Error bars represent standard deviation between triplicate samples; experiments were repeated at least 3 times. (B) Real-time PCR for GDF15 in BT474 pCMV stable empty vector control clone (pCMV) and GDF15 stable clones 2, 3, and 5 (C2, C3, and C5). Values reflect fold change in GDF15 transcript level normalized to RPLPO housekeeping gene. Error bars represent standard deviation between triplicate samples; experiments were repeated at least 3 times. (C-D) BT474 parental, pCMV empty vector control clone (pCMV), and GDF15 stable clones 2 and 3 (C2, C3) were fixed, stained with propidium iodide, and analyzed for DNA content by flow cytometry. The percentage of cells in each cell cycle phase is shown per cell line (C) (white, G0/G1; gray, S; black, G2/M). Error bars represent standard deviation between triplicate samples; experiments were repeated at least 3 times. Representative cell cycle histograms are shown per line (D). 
overexpression of GDF15 in BT474 (Figure 2B) resulted in a 3-fold increase in the percentage of cells in $\mathrm{S}$ phase compared with parental and empty vector control cells (Figure 2C-2D).

We previously found that GDF15 induces EMT in ovarian cancer cells [18]. To determine if stable GDF15 overexpression also promotes EMT in breast cancer cells, we examined expression of mesenchymal and epithelial markers by western blotting. Stable GDF15overexpressing clones exhibited dramatic downregulation of the epithelial marker E-cadherin, and upregulation of mesenchymal markers N-cadherin, vimentin, and transcription factor FoxM1 (Figure 3A). Expression levels of mesenchymal transcription factors Snail, Zeb-1, and Slug were also increased (Figure 3B), with phenotypic morphological changes consistent with acquisition of a mesenchymal phenotype (Figure 3C). EMT is associated with increased potential for migration and invasion. Consistent with this concept, stable overexpression of GDF15 conferred spheroid-forming capability to breast cancer cells, in contrast to parental cells, which did not form spheroids in 3-d culture (Figure 3D). GDF15overexpressing breast cancer cells also demonstrated significantly increased invasion through basement membrane matrix (Figure 3E).

\section{IGF-1R-FoxM1-MMP signaling underlies GDF15-mediated EMT in breast cancer}

We previously demonstrated the importance of IGF-1R as a major upstream mediator of breast cancer cell EMT and invasion [21, 22]. Stable overexpression of GDF15 resulted in $\sim 2$-fold increase in total and phosphorylated IGF-1R relative to empty vector control (Figure 4A). Treatment of stable GDF15-overexpressing cells with IGF-1R-targeted antibody alpha IR3 reduced expression of IGF-1R and induced expression of epithelial marker E-cadherin (Figure 4B). IGF-1R inhibition also rescued the invasive phenotype of GDF15-overexpressing stable cells without significantly affecting control cells

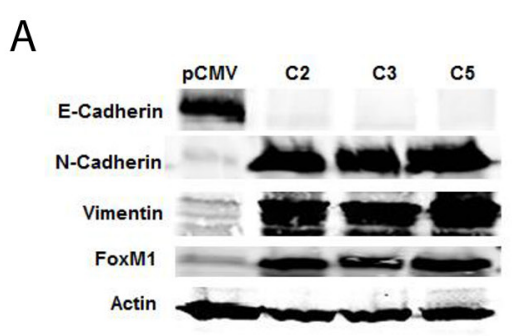

D

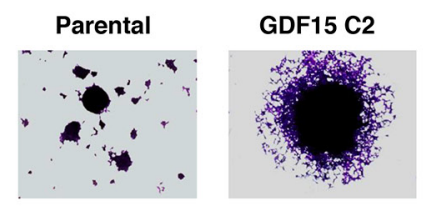

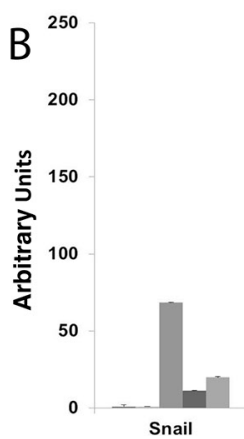

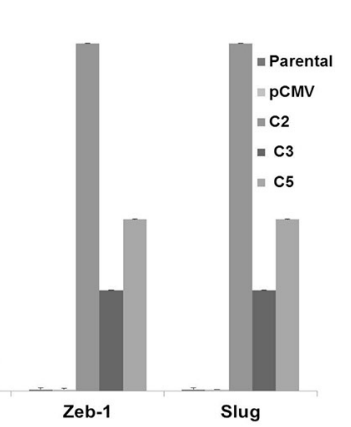

C

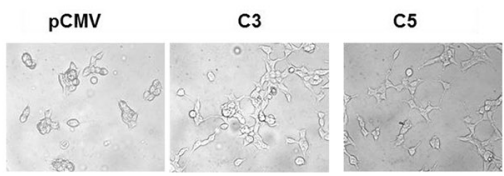

$E$

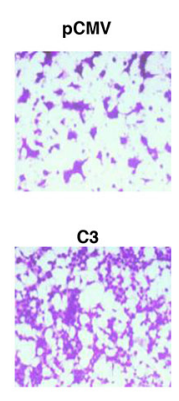

C2

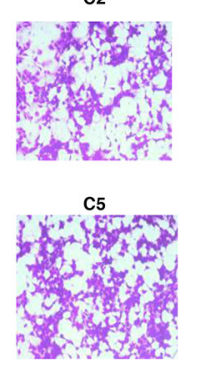

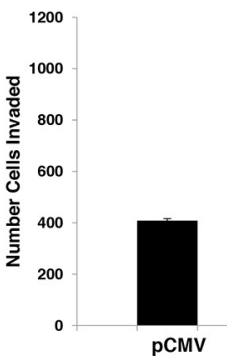

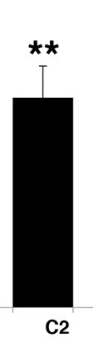

Figure 3: GDF15 induces epithelial mesenchymal transition and invasion in breast cancer cells. (A) Total protein wholecell lysates were collected from BT474 pCMV stable empty vector control clone (pCMV) and GDF15 stable clones 2, 3, and 5 (C2, C3, and C5). Western blots were performed for E-Cadherin, N-Cadherin, vimentin, and FoxM1; actin was measured as a loading control. Blots were repeated at least three times, and representative blots are shown. (B) Real-time PCR for Snail, Zeb-1 and Slug in BT474 parental, pCMV stable empty vector control clone (pCMV) and GDF15 stable clones 2, 3, and 5 (C2, C3, and C5). Values reflect fold change in transcript normalized to $R P L P O$ housekeeping gene. Error bars represent standard deviation between triplicate samples; experiments were repeated at least 3 times. (C) BT474 pCMV empty vector control clone (pCMV) and GDF15 stable clones 3 and 5 (C3 and C5) were imaged at $10 \times$ magnification to evaluate changes in morphology. (D) Representative images of spheroid cultures are shown for BT474 parental and GDF15 stable clone 2 (C2). (E) BT474 stable empty vector control clone (pCMV) and GDF15 stable clones 2, 3, and 5 (C2, C3, and C5) were plated in basement membrane matrix mimic (Matrigel)-coated Boyden chambers in serum-free media; 10\% FBS was added to the well below each chamber as a chemo-attractant. After 24 hours, cells were fixed and stained. Representative photos of invading cells are shown at $20 \times$ magnification. The total number of invading cells was counted in 10 random fields; the average number of invading cells is shown for triplicate cultures per cell line; student's t-test, ${ }^{* *} \mathrm{p}<0.005,{ }^{*} \mathrm{p}<0.05$. 
(Figure 4C). These results suggest that IGF-1R activation contributes to the EMT and invasiveness of GDF15positive breast cancers.

To further elucidate the molecular mechanism through which GDF15 enhances breast cancer cell invasion, we measured expression levels of matrix metalloproteinases (MMP) MMP2 and MMP9, which are transcriptional targets of FoxM1 and mediators of cancer cell invasion. Stable GDF15-overexpressing clones demonstrated significant upregulation of MMP2 and MMP9 (Figure 5A). Treatment with the broadspectrum MMP inhibitor GM6001 significantly reduced invasiveness of stable GDF15-overexpressing clones (Figure 5B), suggesting that MMPs contribute to the invasive phenotype of GDF15-overexpressing breast cancer cells.

Increased FoxM1 expression contributes to cancer cell invasiveness [23]. To determine if FoxM1 upregulation contributes to the increased invasiveness observed in our model system, we transiently knocked down FoxM1 expression. Downregulation of FoxM1 significantly decreased invasion (Figure 6A) to the level of control cells, and reduced expression of MMP2 and MMP9 (Figure 6B).

Similar to stable GDF15-overexpressing BT474 clones, HER2-positive JIMT1 cells stimulated with $2 \mathrm{ng} / \mathrm{mL}$ or $20 \mathrm{ng} / \mathrm{mL}$ rhGDF15 exhibited a 1.5- to 2-fold increase in IGF-1R phosphorylation and expression (Figure 7A). Despite
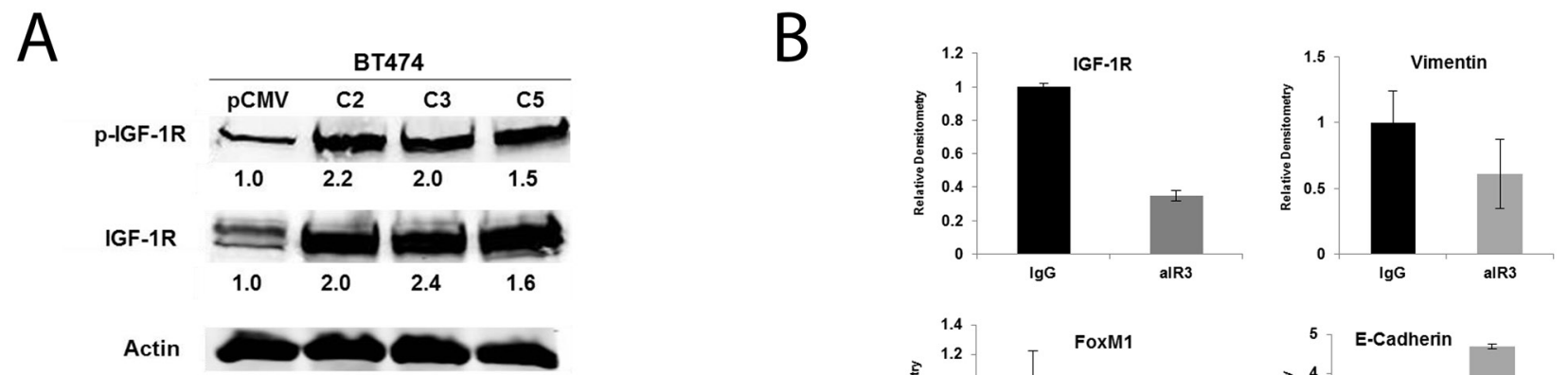

Actin
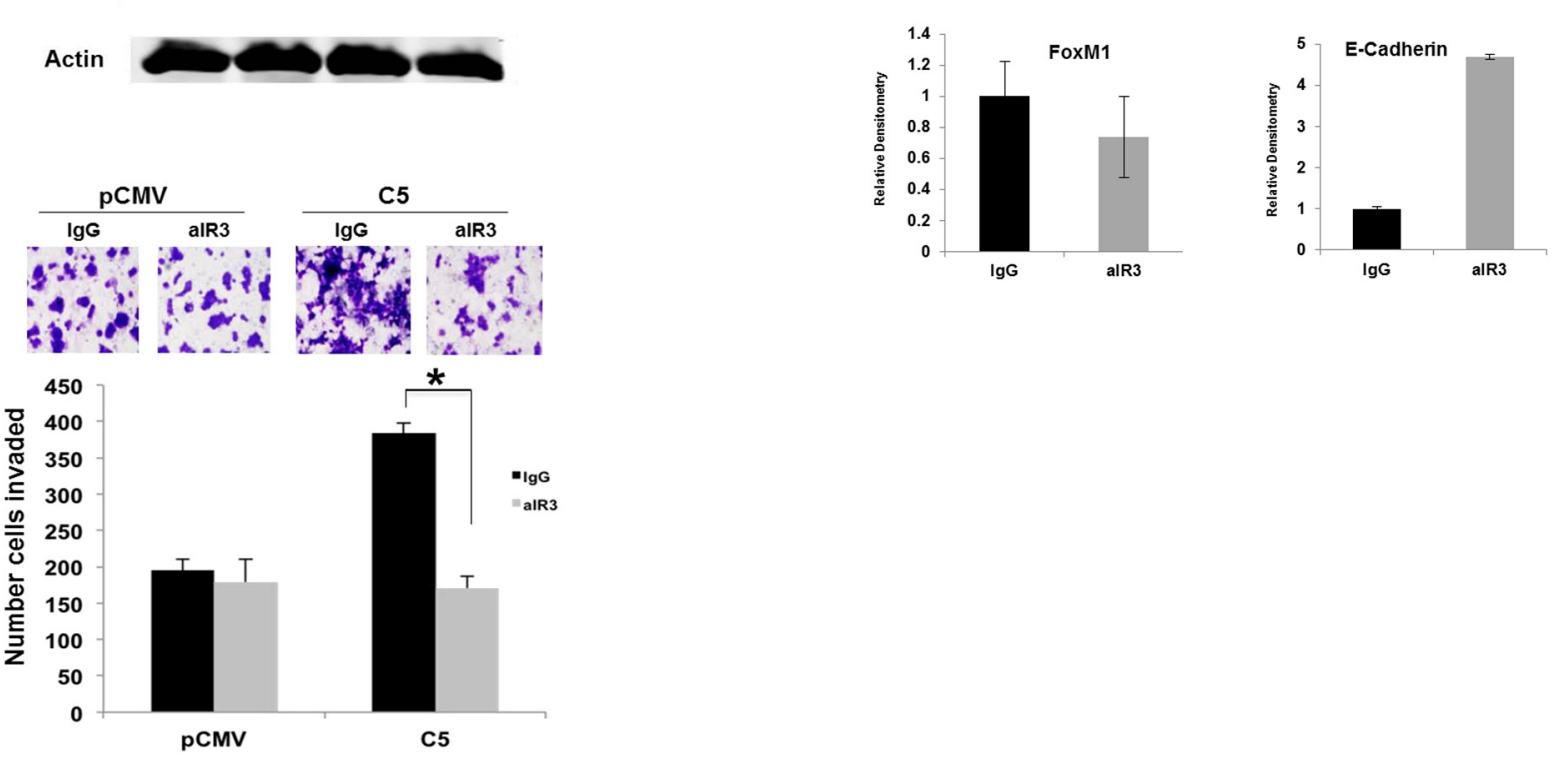

Figure 4: IGF-1R activation contributes to EMT and invasion of GDF15-overexpressing breast cancer cells. (A) Total protein lysates were collected from BT474 stable empty vector control clone (pCMV) and GDF15 stable clones 2, 3, and 5 (C2, C3, and C5). Western blots were performed for p-Tyr1131 IGF-1R and total IGF-1R; actin was probed as loading control. Experiments were repeated 3 times; representative blots are shown. Quantification (shown beneath each band) was normalized to actin and performed using Odyssey Li-Cor imaging software. (B) BT474 GDF15 stable clone 2 (C2) cells were treated with normal mouse IgG control or $0.25 \mu \mathrm{g} / \mathrm{mL}$ alpha IR3 (aIR3) IGF-1R monoclonal antibody for 48 hours. Western blots of total protein lysates were performed for total IGF-1R, vimentin, FoxM1, and E-Cadherin. Bar graphs show quantification relative to actin loading control, and was performed using Odyssey Li-Cor imaging software. Error bars represent standard deviation between triplicates; experiments were performed at least 3 times. (C) BT474 stable empty vector control clone (pCMV) and BT474 GDF15 stable clone 5 (C5) cells were pre-treated with normal mouse IgG or $0.25 \mu \mathrm{g} / \mathrm{mL}$ alpha IR3 (aIR3) IGF-1R monoclonal antibody for 24 hours. Cells were then seeded in Matrigel-coated Boyden chambers in serum-free media plus control IgG or aIR3; 10\% FBS was added to the well as a chemo-attractant. After 24 hours of invasion, cells in chambers were fixed and stained. Representative photos of invading cells are shown at $20 \times$ magnification. The total number of invading cells was counted in 10 random fields; the average number of invading cells is shown for triplicate cultures per cell line, ${ }^{*} \mathrm{p}<0.05$. 

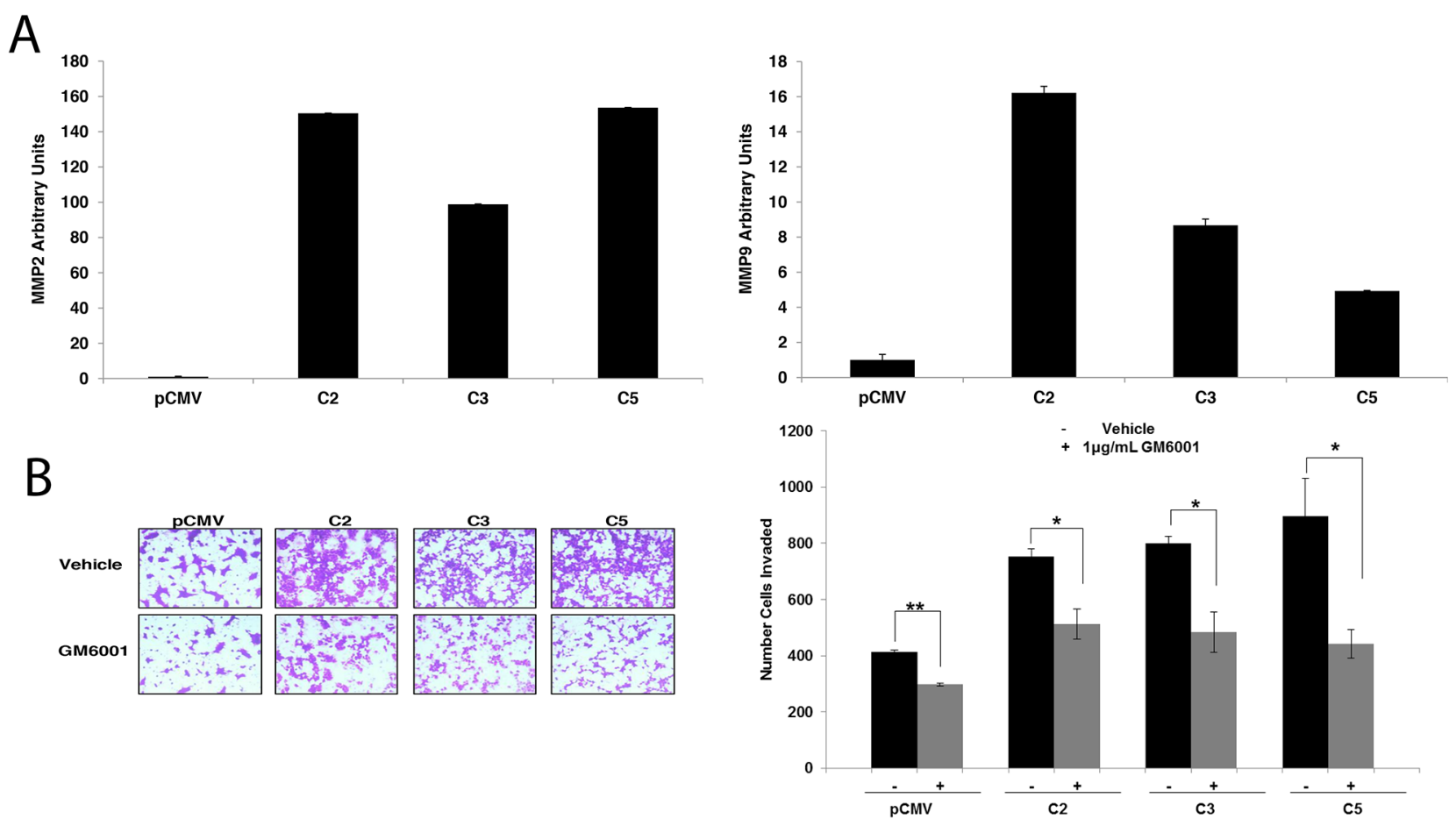

Figure 5: Matrix metalloproteinases (MMPs) mediate invasion of GDF15-overexpressing breast cancer cells. (A) Real-time PCR of total RNA from BT474 pCMV empty vector control clone (pCMV) and GDF15 stable clones (C2, C3, and C5) for MMP2 (left graph) and MMP9 (right graph). Values reflect average fold in transcript normalized to internal control RPLPO relative to pCMV group. Error bars represent standard deviation between triplicate samples; experiments were repeated 3 times. (B) BT474 pCMV empty vector control clone (pCMV) and GDF15 stable clones (C2, C3 and C5) were plated in serum-free media in Matrigel-coated Boyden chambers and treated with vehicle control or $1 \mu \mathrm{g}$ pan-MMP inhibitor GM6001 for 24 hours, after which cells were fixed and stained. Representative photos of invading cells are shown at 20× magnification. The total number of invading cells was counted in 10 random fields; the average number of invading cells is shown for triplicate cultures per cell line; student's t-test, ${ }^{* *} \mathrm{p}<0.005,{ }^{*} \mathrm{p}<0.05$.
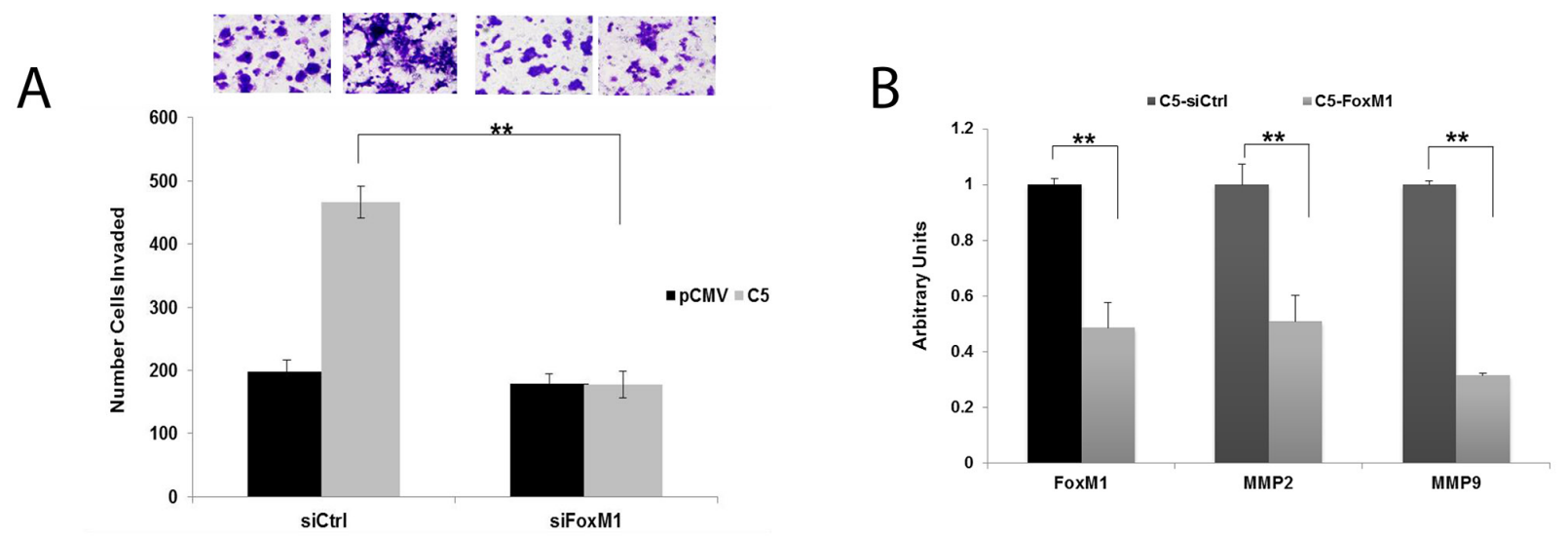

Figure 6: FoxM1 promotes invasion and upregulation of MMP2 and MMP9 in GDF15-overexpressing breast cancer cells. (A) BT474 stable empty vector control clone (pCMV) and GDF15 stable clone 5 (C5) were transfected with $100 \mathrm{nM}$ control siRNA (siCtrl) or FoxM1 siRNA (siFoxM1) for 48 hours, and then plated in serum-free media in Matrigel-coated Boyden chambers. After 24 hours, cells were fixed and stained. Representative photos of invading cells are shown at $20 \times$ magnification. The total number of invading cells was counted in 10 random fields; the average number of invading cells is shown for triplicate cultures per cell line; student's t-test, ** $\mathrm{p}<0.005$. (B) BT474 GDF15 stable clone 5 (C5) cells were transfected with $100 \mathrm{nM}$ control siRNA (siCtrl) or FoxM1 siRNA (FoxM1) for 48 hours. Real-time PCR was performed for FoxM1, MMP2, and MMP9. Values reflect average fold in transcript normalized to internal control RPLPO. Error bars represent standard deviation between triplicate samples; experiments were repeated 3 times, ${ }^{* *} \mathrm{p}<0.005$. 
blocking rhGDF15-mediated induction of IGF-1R (Figure 7B), the IGF-1R antibody alpha IR3 only partially rescued the increased expression of mesenchymal markers (Figure 7C) and invasion (Figure 7D). Knockdown of FoxM1 (Figure 8A) rescued EMT (Figure 8B) and invasiveness (Figure 8C) of GDF15-overexpressing breast cancer cells.

\section{Knockdown of GDF15 inhibits breast cancer invasion}

Based on data indicating that GDF15 mediates EMT and invasion, we hypothesized that knockdown of GDF15 expression would block invasiveness of breast cancers that overexpress GDF15. Using siRNA, GDF15 was transiently knocked down in HER2-positive BT474 empty vector pCMV control, BT474 GDF15-overexpressing stable clone, and triple-negative MDA-MB-231 breast cancer cells, which have endogenous overexpression of GDF15 (Figure 9B). Knockdown of GDF15 significantly inhibited breast cancer invasion through basement membrane matrix (Figure 9A). These results establish a functional role for GDF15 in breast cancer invasion, and support further investigation into GDF15-targeting as a potential therapeutic strategy.

\section{DISCUSSION}

In the current study, we provide mechanistic insights into the signaling pathways driving GDF15-mediated EMT and invasion in breast cancer. GDF15 overexpression activated IGF-1R signaling with subsequent upregulation of FoxM1 and target MMPs, increased expression of
A
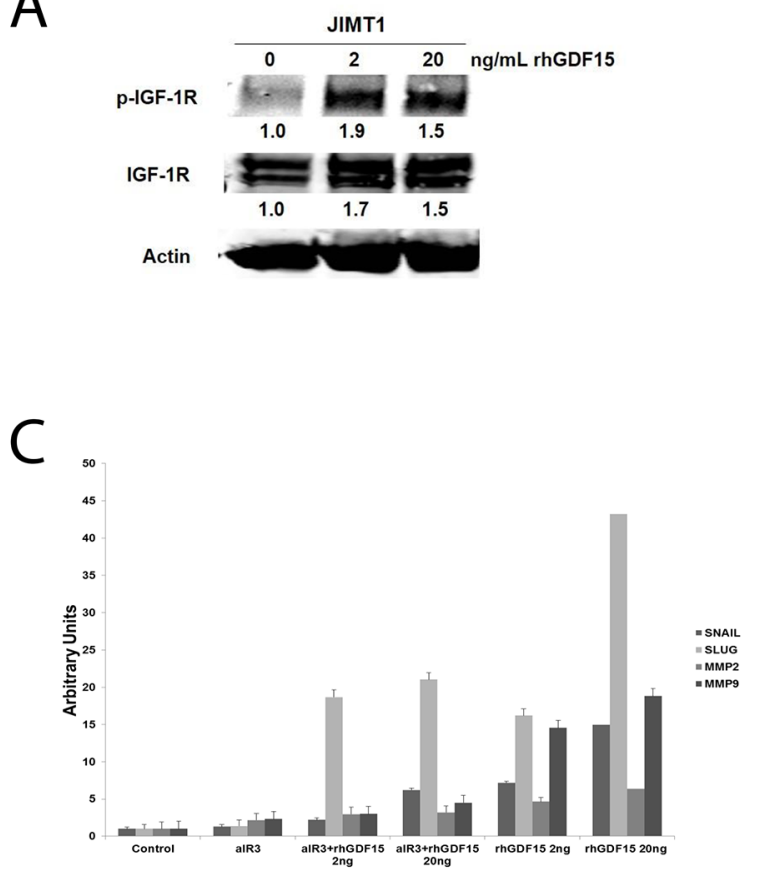

B
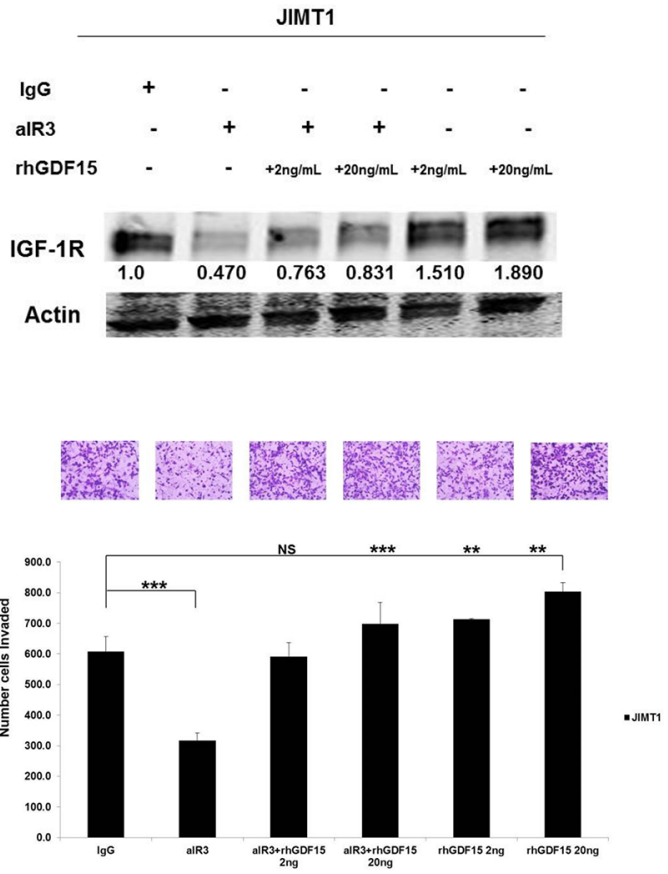

Figure 7: Effects of IGF-1R inhibition on GDF15-stimulated EMT and invasion. (A) JIMT1 cells were serum starved for 24 hours, and then stimulated with 2 or $20 \mathrm{ng} / \mathrm{mL}$ of recombinant human GDF15 (rhGDF15) for another 24 hours. Western blots of total protein lysates are shown for p-Tyr1131 IGF-1R and total IGF-1R; actin was probed as loading control. Experiments were repeated 3 times; representative blots are shown. Quantification (shown beneath each band) was normalized to actin and performed using Odyssey Li-Cor imaging software. (B) JIMT-1 cells were pretreated for 24 hours with control IgG or $0.25 \mu \mathrm{g} / \mathrm{ml}$ alpha IR3 (aIR3) in serum-free media, and then stimulated with 2 or $20 \mathrm{ng} / \mathrm{mL}$ of recombinant human GDF15 (rhGDF15) for another 24 hours. Western blots of total protein lysates are shown for total IGF-1R with actin as loading control. Experiments were repeated 3 times; representative blots are shown. Quantification (shown beneath each band) was normalized to actin and performed using Odyssey Li-Cor imaging software. (C) JIMT-1 cells were pretreated for 24 hours with control IgG or $0.25 \mu \mathrm{g} / \mathrm{ml}$ alpha IR3 (aIR3) in serum-free media, and then stimulated with 2 or $20 \mathrm{ng} / \mathrm{mL}$ of recombinant human GDF15 (rhGDF15) for another 24 hours. Real-time PCR was performed for SNAIL, SLUG, MMP2, and MMP9. Values reflect average fold in transcript normalized to internal control RPLPO. Error bars represent standard deviation between triplicate samples; experiments were repeated 3 times. (D) JIMT-1 cells were pretreated for 24 hours with control IgG or 0.25 $\mu \mathrm{g} / \mathrm{ml}$ alpha IR3 (aIR3) in serum-free media, and then seeded in Matrigel-coated Boyden chambers in serum-free media with 10\% FBS in the lower chamber as chemoattractant. Drug treatment was continued (in indicated samples), and 2 or $20 \mathrm{ng} / \mathrm{mL}$ of recombinant human GDF15 (rhGDF15) was added to the chambers of treatment groups where indicated. After 24 hours of invasion, photos were taken at 20× magnification; representative photos are shown. The number of invaded cells is shown per group; error bars represent standard deviation between triplicate samples, ${ }^{*} \mathrm{p}<0.05$. 
EMT mediators, and increased cellular invasion (Figure 10). These data suggest that the inflammatory cytokine GDF15 contributes to breast cancer progression in part by activating signaling pathways that control EMT and cellular invasion.

IGF-1R activation and overexpression promote EMT in many tumor types. In breast cancer, IGF-1R signaling induces EMT, migration, and invasion in HER2-positive and triple-negative breast cancer $[22,24]$. Acquisition of a mesenchymal phenotype has been reported to confer stem cell-like and migratory characteristics, resulting in recurrent metastases and drug resistance in multiple tumor models $[25,26]$. Consistent with the GDF15-driven EMT we observed in our studies, GDF15 was recently shown to maintain stem cell characteristics in breast cancer cell lines [27]. The mechanisms through which IGF-1R promotes a switch to a mesenchymal phenotype are not fully understood. However, IGF-1R activation is known to stimulate MEK-Erk1/2 and PI3K-Akt signaling, which in turn regulate EMT transcription factors. We previously demonstrated that GDF15 induces PI3K and
Erk1/2 phosphorylation in HER2-overexpressing breast cancer cells, in association with drug resistance [27]. Further, MEK inhibition blocked the ability of GDF15 to induce tumor sphere formation [16], indicating that MEK activation downstream of IGF-1R activation may contribute to GDF15-stimulated EMT. These data provide rationale for evaluating IGF-1R and MEK inhibition as a potential therapeutic strategy in mesenchymal GDF15positive breast cancers.

In addition to regulating expression of EMT markers, IGF-1R inhibition blocked invasion of GDF15overexpressing cells with reduced FoxM1 expression. We previously reported that FoxM1 is a critical mediator of IGF-1R-stimulated invasion in breast cancer cells [22]. The current study further supports FoxM1 as a mediator of IGF-1R-mediated invasion. FoxM1 knockdown reduced invasion, expression of mesenchymal transcription factors, and upregulation of MMP2 and MMP9 in BT474derived GDF15 stable clones and JIMT1 cells. These data demonstrate that GDF15-IGF-1R-FoxM1 signaling stimulates breast cancer invasion, with IGF-1R and
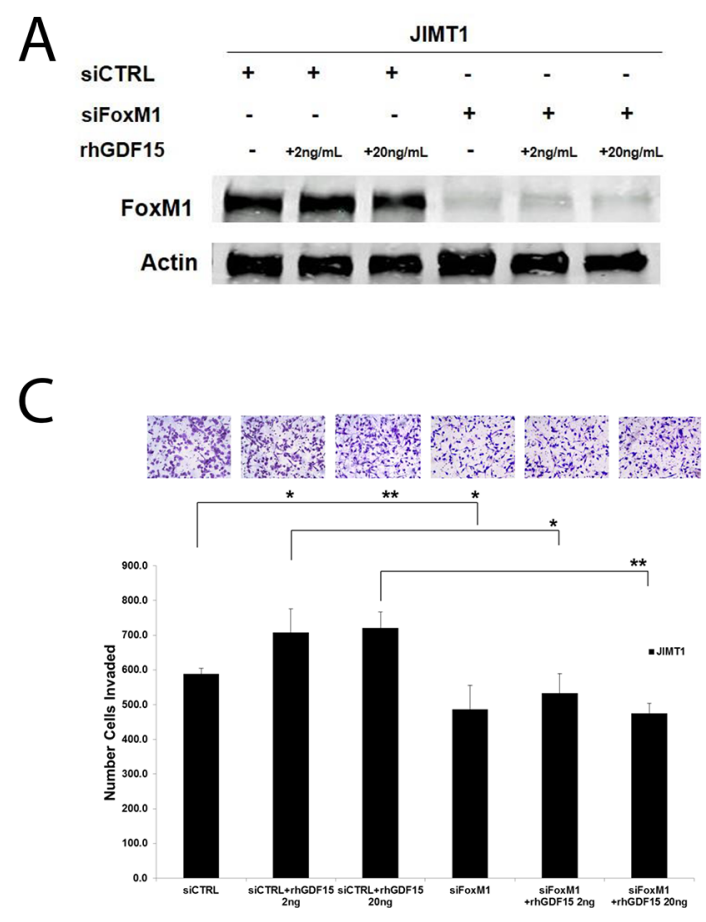

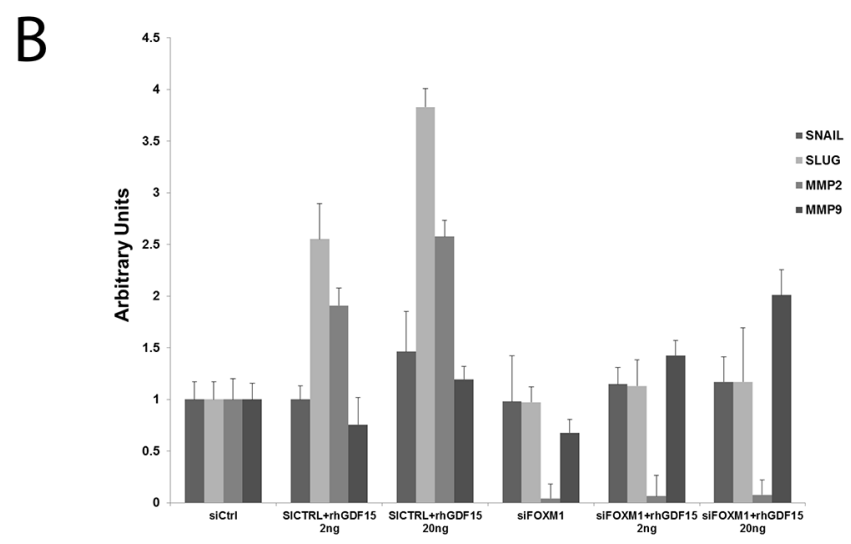

Figure 8: FoxM1 mediates GDF15-simulated EMT and invasion. (A) JIMT-1 cells were transfected with $100 \mathrm{nM}$ control siRNA (siCtrl) or FoxM1 siRNA (siFoxM1) for 24 hours, and then stimulated with 2 or $20 \mathrm{ng} / \mathrm{mL}$ recombinant human GDF15 (rhGDF15) for another 24 hours. Western blots of total protein lysates are shown for total FoxM1 with actin as loading control. (B) JIMT-1 cells were transfected with $100 \mathrm{nM}$ control siRNA (siCtrl) or FoxM1 siRNA (siFoxM1) for 24 hours, and then stimulated with 2 or 20 ng/mL recombinant human GDF15 (rhGDF15) for another 24 hours. Real-time PCR was performed for Snail, Slug, MMP2, and MMP9. Values reflect average fold in transcript normalized to internal control RPLPO. Error bars represent standard deviation between triplicate samples; experiments were repeated 3 times. (C) JIMT-1 cells were transfected with $100 \mathrm{nM}$ control siRNA (siCtrl) or FoxM1 siRNA (siFoxM1) for 24 hours, and then plated in serum-free media in Matrigel-coated Boyden chambers. Recombinant human GDF15 (rhGDF15; 2 or 20 ng/ $\mathrm{mL}$ ) was added to lower chambers where indicated. After 24 hours, cells were fixed and stained; representative photos of invading cells are shown at $20 \times$ magnification. The total number of invading cells was counted in 10 random fields; the average number of invading cells is shown for triplicate cultures per cell line, ${ }^{* *} \mathrm{p}<0.005,{ }^{*} \mathrm{p}<0.05$. 

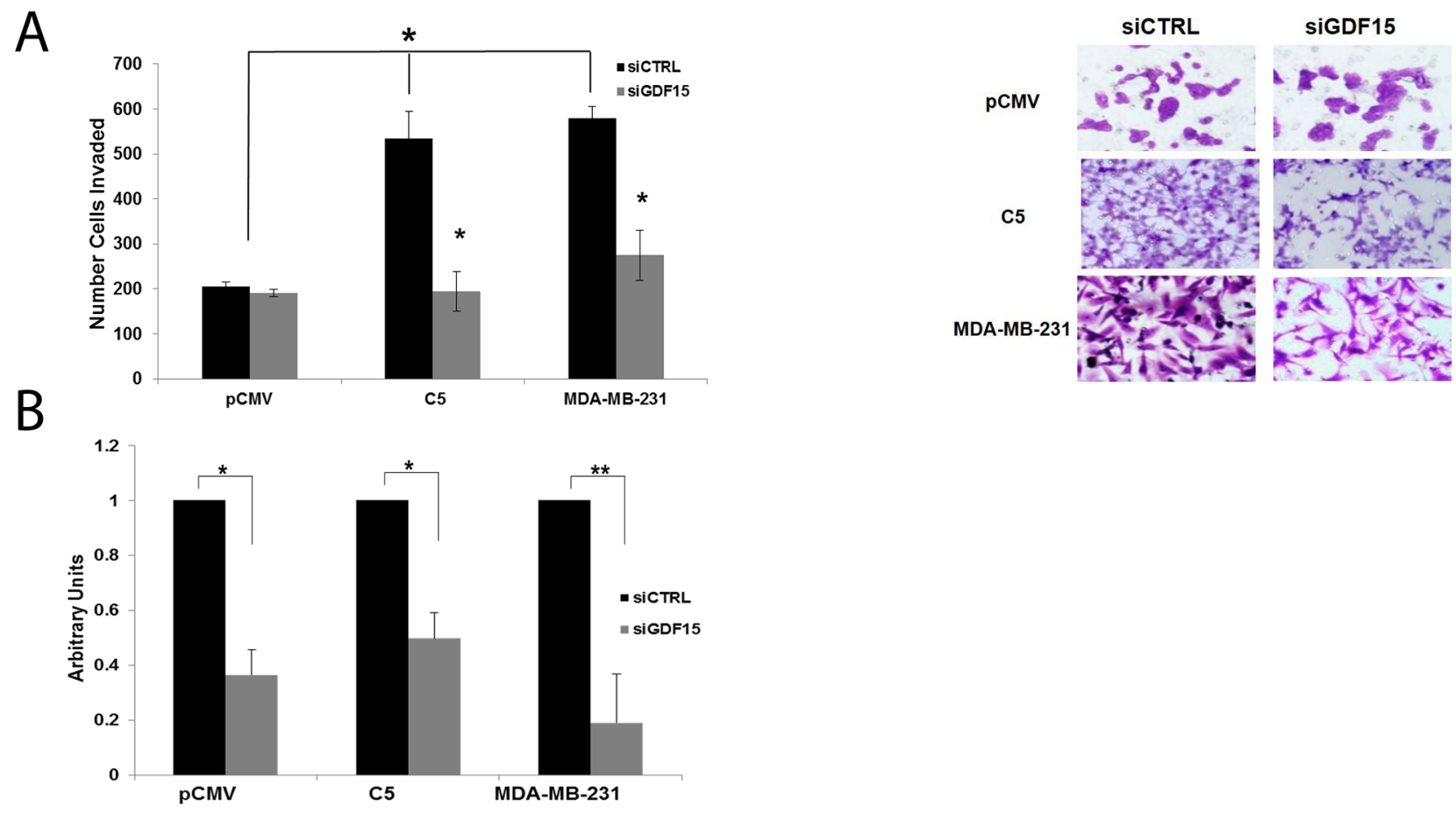

Figure 9: GDF15 knockdown inhibits invasion of breast cancer cells. (A) BT474 stable empty vector control clone (pCMV), BT474 GDF15 stable clone 5 (C5), and MDA-MB-231 cells were transfected with $100 \mathrm{nM}$ siRNA control (siCtrl) or GDF15 siRNA (siGDF15). After 24 hours, transfected cells were plated in serum-free media in Matrigel-coated Boyden chambers with $10 \%$ FBS in the wells as a chemoattractant. After 24 hours, cells were fixed and stained. Representative photos of invading cells are shown at $20 \times$ magnification. The total number of invading cells was counted in 10 random fields; the average number of invading cells is shown for triplicate cultures per cell line, ${ }^{*}$ p $<0.05$. (B) BT474 stable empty vector control clone (pCMV), BT474 GDF15 stable clone 5 (C5), and MDA-MB-231 cells were transfected with $100 \mathrm{nM}$ siRNA control (siCtrl) or GDF15 siRNA (siGDF15) for 48 hours. Real-time PCR was performed to confirm GDF15 knockdown. Values reflect the fold change in transcript normalized to RPLPO housekeeping gene. Error bars represent standard deviation between triplicate samples; experiments were repeated twice; ${ }^{* *} \mathrm{p}<0.005,{ }^{*} \mathrm{p}<0.05$.

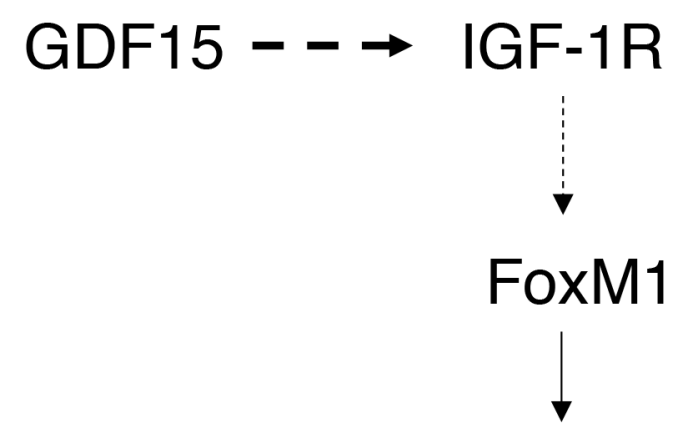

\section{EMT TFs, MMPs}

Figure 10: Schematic of model. GDF15 activates IGF-1R signaling and induces expression of FoxM1, which upregulates expression of EMT transcription factors (TFs), including Snail and Slug, and induces expression of matrix metalloproteinases (MMPs), stimulating EMT and breast cancer cell invasion. 
FoxM1 representing potential downstream targets for inhibiting GDF15-mediated invasion.

Additional mechanisms are likely to contribute to GDF15-mediated EMT and invasion. Some studies suggest that GDF15 induces phosphorylation of TGF- $\beta$ signaling effectors Smad2 and Smad3 [14, 17], which are recognized mediators of EMT [28]. Recent studies identified the GDF15 receptor as GFRAL, a distant relative of TGF- $\beta$ family members [11-13]. Thus, future evaluation of the role of GFRAL and associated signaling pathways in EMT and invasion of GDF15-overexpressing breast cancer cells is warranted. GDF15 also activates focal adhesion kinase (FAK) signaling, driving prostate cancer metastasis [29]. We previously reported that IGF$1 \mathrm{R}$ regulates FAK signaling and EMT in triple-negative breast cancer. Further, we and others previously have shown that GDF15 activates HER2 kinase activity [14, $24,30]$, resulting in acquired and intrinsic resistance to HER2-targeted antibody therapy [27]. These results are consistent with previous reports that IGF-1R/HER2 crosssignaling causes trastuzumab resistance, and suggest that GDF15 overexpression may represent one mechanism driving activation of the HER2 and IGF-1R receptor kinase signaling network and drug resistance.

Although increased expression of GDF15 is associated with advanced disease in patients with multiple types of malignancies, limited data are available regarding the expression levels of GDF15 in breast cancer. Welsh et al. [10] examined changes in gene expression of secreted proteins in the sera of cancer patients representing 10 different tumor types. Serum levels of GDF 15 were elevated in patients with metastatic colorectal $(8 / 8)$, prostate $(8 / 9)$, and breast $(6 / 10)$ cancers when compared with sera from normal controls. Wollmann et al. [31] compared GDF15 transcript levels in 10 breast tumor samples matched with adjacent normal tissue controls, and found higher GDF15 expression in half of the tumor samples. Thus, according to these studies, which included a relatively small number of patient samples, GDF15 expression was elevated in $50 \%$ to $60 \%$ of serum or tumor tissue specimens from patients with breast cancer. Consistent with those studies, we demonstrate by IHC staining that GDF 15 is expressed in $66 \%(397 / 605)$ of patients with breast cancer.

Sasahara et al. [16] recently reported that GDF15 expression was higher in breast cancer tissues compared with normal controls, with HER2-positive tumors demonstrating the highest expression levels of GDF15. We examined potential associations between GDF15 IHC staining and available clinical data, which included age, tumor size, tumor grade, disease involving $>3$ lymph nodes, ER and HER2 positivity, and overall survival. GDF15 expression was significantly associated with high tumor grade, and ER-negative or HER2-positive status. A limitation of our IHC study was that most patients in this cohort had low-grade tumors with either non-metastatic disease or fewer than 3 lymph node metastases. Thus, this cohort may represent a relatively low-risk population or subgroup with primarily localized or locally invasive disease. Future analyses should examine cohorts that include a greater percentage of patients with lymph nodepositive or metastatic disease to determine if GDF15 overexpression is associated with metastasis, recurrence, or reduced survival rates in patients with advanced-stage disease, as is reported in other tumor types [32, 33]. These studies should also evaluate potential subtype-specificity of GDF15 expression in HER2-positive and ER-negative breast cancer, based on results presented here, and associations between GDF15 expression and treatment response or survival.

In summary, while GDF15 exhibits pleiotropic effects in cancer cells [7], the majority of studies support a role for GDF15 in disease progression, with overexpression linked to EMT, invasion and metastasis. Our studies are the first to report activation of IGF1R-FoxM1 as a mechanism of invasion in GDF15overexpressing breast cancers, providing rationale for preclinical evaluation of treatments that co-target IGF-1R and FoxM1. Further, based on the reduced invasiveness of HER2-positive and triple-negative breast cancers in response to GDF15 knockdown, future studies should evaluate GDF15 as a potential molecular target in breast cancer.

\section{MATERIALS AND METHODS}

\section{Materials}

The IGF-1R antibody alpha IR3 (Calbiochem; San Diego, CA) was provided at a stock concentration of 1 mg/mL. GDF15 small interfering RNA (siRNA; sc-39798) and control siRNA (sc-37007) (Santa Cruz Biotechnology; Dallas, TX) were resuspended in RNAse-free water. The IGF-1R antibody alpha IR3 ( $\alpha$-IR3; Calbiochem, San Diego, CA) was provided at a stock concentration of 1 mg/mL. Recombinant human GDF15 (rhGDF15; R\&D Systems, 614 McKinley Place NE, Minneapolis, MN 55413 ) was dissolved in $4 \mathrm{mM} \mathrm{HCl}$ containing $0.1 \% \mathrm{BSA}$; the solvent (HCl-BSA) was used as vehicle control. The pan-MMP inhibitor GM6001 (Millipore; Temecula, Ca) was provided at a stock concentration of $1 \mathrm{mg} / \mathrm{mL}(2.5$ $\mathrm{mM}$ ) in DMSO.

\section{IHC}

Breast tumor microarrays (TMAs) kindly provided by Dr. Fabrice Andre (Gustave Roussy Cancer Center, Villejuif, France) consisted of paraffin-embedded breast tumor tissues obtained from 605 patients diagnosed with breast cancer. Tumor tissues were spotted in triplicate per patient. Among 605 patients, 592 patients had 
recorded information for tumor size, grade, lymph node status, and ER status; thus, correlations were performed using data from these 592 patients. IHC staining was performed using a standard immunoperoxidase procedure as previously described [27]. Tissues were deparaffinized by heating at $60^{\circ} \mathrm{C}$, passaging through xylene and alcohol grades, and ultimately water. Antigen retrieval was performed by boiling in $10 \mathrm{mM}$ citrate buffer, pH 6.0 for 10 minutes ( $\mathrm{min}$ ), and cooling in the same buffer for $30 \mathrm{~min}$. Endogenous peroxidase was quenched by incubating with $0.3 \% \mathrm{H}_{2} \mathrm{O}_{2}$ in methanol for 15 min. After washing with water and PBS/TBS, TMA slides were incubated in 10\% swine serum (Dako North America, Inc., 6392 Via Real, Carpinteria, CA 93013) for 1 hour (h) to block nonspecific background staining. TMAs were then stained with rabbit polyclonal antihuman GDF15 (also known as MIC-1; antibody 3249; dilution 1:100; Cell Signaling Technology, Inc., 3 Trask Lane, Danvers, MA 01923) overnight at $4^{\circ} \mathrm{C}$. Secondary antibody staining was then performed with biotinylated anti-rabbit antibody (Dako North America, Inc.), followed by visualization with 3,3-diaminobenzidine solution (DAB+ chromogen; Dako North America, Inc.) and hematoxylin as a counterstain. Slides were washed in water, dehydrated by passing through alcohol grades and xylene, and mounted with Permount (Fisher Scientific, 300 Industry Dr., Pittsburgh, PA 15275). GDF15 staining intensity was viewed under a light microscope, and scored in a blinded manner from 0 to 3 by a breast pathologist at Emory University, i.e., the pathologist had no knowledge of molecular or clinical characteristics of the tumor samples. Correlations between GDF15 score and clinical characteristics were determined by two-tailed Fisher's exact test, with $\mathrm{P}<0.05$ considered statistically significant.

\section{Cell culture}

JIMT1 cells were purchased from DSMZ (Braunschweig, Germany); all other cell lines were purchased from American Type Culture Collection (Manassas, VA). MDA-MB-231, JIMT-1, and BT474 cells were maintained in Dulbecco's Modified Eagle's Medium (DMEM) with $4.5 \mathrm{~g} / \mathrm{L}$ glucose, glutamine, and sodium pyruvate (Corning; Manassas, VA) with 10\% FBS and $1 \%$ penicillin/streptomycin. All cells were cultured in humidified incubators at $37^{\circ} \mathrm{C}$ with $5 \% \mathrm{CO}_{2}$.

\section{Creation of stable GDF15-overexpressing clones}

BT474 cells were transfected with $3 \mu \mathrm{g}$ plasmid DNA (pCMV empty vector or pCMVmyc-GDF15, both from Origene, Rockville, MD) using Lipofectamine (Invitrogen, Carlsbad, CA) and DMSO shock. After 24-36 $\mathrm{h}$, cells were maintained in $200 \mu \mathrm{g} / \mathrm{mL}$ of G418 to select successfully transfected cells. After approximately 2-3 weeks, multiple surviving clones were isolated and tested by real-time PCR for GDF15 expression.

\section{Transfection}

Cells were plated in antibiotic-free media at a concentration of $2 \times 10^{5}$ cells $/ \mathrm{mL}$. The next day, cells were transfected using Lipofectamine 2000 (Invitrogen; Carlsbad, CA) with $100 \mathrm{nM}$ GDF15 siRNA, 100 nM FOXM1 siRNA, or control siRNA (Santa Cruz Biotechnology) according to the manufacturer's protocol. Media was changed after $6 \mathrm{~h}$ of transfection and replaced with complete media. Cells were harvested after 24 or $48 \mathrm{~h}$.

\section{Cell stimulation}

Cells were plated and serum starved for at least 24 $\mathrm{h}$ prior to stimulation with vehicle control, 2 or $20 \mathrm{ng} / \mathrm{mL}$ of rhGDF15 for varying time points. Experiments were repeated at least twice.

\section{Spheroid migration assays}

Cells were seeded $\left(5 \times 10^{4}\right)$ in $1 \%$ agar-coated 96-well plates and cultured for $48 \mathrm{~h}$ in a humidified atmosphere containing $5 \% \mathrm{CO}_{2}$ at $37^{\circ} \mathrm{C}$. Intact tumor spheroids were carefully transferred to a 96-well plate and cultured in complete media for $24 \mathrm{~h}$. Spheroids and migrated cells were fixed with $100 \%$ methanol, stained with $0.05 \%$ crystal violet, and observed using a normal light microscope $(20 \times)$ and Olympus DP-30BW digital camera. Eight replicates were included per group, and experiments were repeated three times.

\section{Invasion assays}

Cells were plated in serum-free media in BD BioCoat Matrigel Invasion Chambers (BD Biosciences; Franklin Lakes, NJ) $\left(1 \times 10^{5}\right.$ cells $\left./ \mathrm{mL}\right)$ with $0.75 \mathrm{~mL}$ chemoattractant (culture media containing 10\% FBS) in each well. Depending on the experiment, cells were pretreated with control mouse IgG or alpha IR3 $(0.25 \mu \mathrm{g} / \mathrm{mL})$ added directly to the chamber, or transfected with control siRNA or GDF15 siRNA overnight prior to placing cells in invasion chambers. Non-invading cells were removed from the interior surface of the membrane by scrubbing gently with dry cotton tipped swab. Each insert was then transferred into $100 \%$ methanol for 10 minutes followed by crystal violet staining for 20 minutes. Membranes were washed in water, allowed to air dry completely before being separated from the chamber, and then mounted on slides with permanent mounting medium Permount (Fisher Scientific). Multiple photographs of each sample were taken at $20 \times$ magnification, with triplicates per treatment group. The number of cells was counted in each field, and the sum of cells in all fields was calculated for each sample. Triplicate cultures were included per group, and experiments were repeated at least twice.

\section{Cell cycle analysis}

Cells were harvested, washed twice with DPBS + $10 \%$ FBS, fixed in ice-cold $80 \%$ ethanol, and stored at 
$-20^{\circ} \mathrm{C}$ for at least 24 hours. Fixed cells were incubated in $50 \mu \mathrm{L}$ propidium iodide buffer $(20 \mu \mathrm{g} / \mathrm{mL}$ PI (Sigma), 0.1\% Triton-X 100, $200 \mu \mathrm{g} / \mathrm{mL}$ RNaseA (Promega) in DPBS) for 30 minutes in the dark. Cells were resuspended in $400 \mu \mathrm{L}$ DPBS. Samples were analyzed using a BD FACS Canto II cytometer (BD Biosciences; San Jose, CA) and BD FACS Diva software. Triplicates were included per group, and experiments were repeated at least twice.

\section{Western blotting}

Cells were lysed in RIPA buffer (Cell Signaling; Danvers, MA) supplemented with protease and phosphatase inhibitors (Sigma-Aldrich). Total protein extracts were run on SDS-PAGE and blotted onto nitrocellulose. Blots were probed overnight using the following antibodies from Cell Signaling: rabbit anti-phospho-IGF-1 receptor $\beta$ (Tyr1131) (\#3021, 1:200); rabbit anti-IGF-1 receptor $\beta$ (\#3018, 1:250); and rabbit-anti-N-Cadherin (\#4061, 1:1000). Rabbit anti-GDF15 (\#8479 1:200) was purchased from AbCam (Cambridge, MA). Mouse anti-E-Cadherin (\#610181, 1:1000) was purchased from BD Biosciences (San Jose, CA). Mouse anti-vimentin (Sigma-Aldrich; V6630) was used at 1:1000. Mouse anti- $\beta$-actin monoclonal AC-15 (Sigma-Aldrich) was used at 1:10,000 as a loading control. All primary antibodies were diluted in 5\% BSA/TBS-T. Goat anti-mouse secondary IRDye 800 antibody (\#926$32210,1: 10,000)$ was purchased from Li-Cor Biosciences (Lincoln, NE). Goat anti-rabbit Alexa Fluor 680 secondary antibody (\#1027681, 1:10,000) was purchased from Invitrogen (Grand Island, NY). Protein bands were detected using the Odyssey Imaging System (Li-Cor Biosciences, Lincoln, NE). Blots were repeated at least three times.

\section{Quantitative RT-PCR}

Total RNA was extracted using the RNeasy purification kit (Qiagen; Valencia, CA) and treated with DNase (Invitrogen; Carlsbad, CA). Total RNA was used to prepare cDNA using random primers and the Superscript III first strand synthesis kit (Invitrogen; Carlsbad, CA). Relative levels of mRNA were determined by real-time quantitative PCR using an Applied Biosystems cycler and the TaqMan Universal PCR master mix (4304437; Applied Biosystems; Carlsbad, CA). Primers for RPLPO (Hs99999902_M1), FOXM1 (Hs01073586_M1), GDF15 (Hs00171132_m1), MMP2 (Hs01548733_m1), MMP9 (Hs00234579_m1), E-Cadherin (Hs01023894_m1), SNAIL (Hs00195591_m1), SLUG (Hs00950344_m1), and Zeb-1 (Hs00232783_m1) were obtained from Applied Biosystems (Taq-Man Gene Expression Assays; Carlsbad, CA). After amplification, data were normalized to RPLPO levels and analyzed by delta $\mathrm{Ct}$ method. Triplicates were included per group, and experiments were repeated at least twice.

\section{Statistics}

P-values were determined for experimental versus control treatments by two-tailed student's t-test, ${ }^{*} \mathrm{p}<0.05$, ${ }^{* *} \mathrm{p}<0.005$. IHC correlations were determined by two-tailed Fisher's exact test.

\section{ACKNOWLEDGMENTS AND FUNDING}

RN acknowledges funding from Winship Cancer Institute through the Glenn Breast Cancer Research Scholars Program and Owenby Research Award, and from the Emory University Research Committee. BFP is supported by diversity training supplement R01CA157754-05S1. The authors thank Dr. Fabrice Andre for providing breast tumor tissue arrays, and Dr. Amy Adams for technical assistance. We acknowledge the Winship Cancer Institute Cell Imaging and Microscopy Center.

\section{CONFLICTS OF INTEREST}

The authors declare no conflicts of interest.

\section{REFERENCES}

1. Bootcov MR, Bauskin AR, Valenzuela SM, Moore AG, Bansal M, He XY, Zhang HP, Donnellan M, Mahler S, Pryor K, Walsh BJ, Nicholson RC, Fairlie WD, et al. MIC1 , a novel macrophage inhibitory cytokine, is a divergent member of the TGF-beta superfamily. Proc Natl Acad Sci U S A. 1997; 94: 11514-9.

2. Wang X, Baek SJ, Eling TE. The diverse roles of nonsteroidal anti-inflammatory drug activated gene (NAG-1/GDF15) in cancer. Biochem Pharmacol. 2013; 85: 597-606. https://doi.org/10.1016/j.bcp.2012.11.025.

3. Adela R, Banerjee SK. GDF-15 as a Target and Biomarker for Diabetes and Cardiovascular Diseases: A Translational Prospective. J Diabetes Res. 2015; 2015: 490842. https:// doi.org/10.1155/2015/490842.

4. Jiang R, Li Y, Xu Y, Zhou Y, Pang Y, Shen L, Zhao Y, Zhang J, Zhou J, Wang X, Liu Q. EMT and CSC-like properties mediated by the IKKbeta/IkappaBalpha/RelA signal pathway via the transcriptional regulator, Snail, are involved in the arsenite-induced neoplastic transformation of human keratinocytes. Arch Toxicol. 2013; 87: 991-1000. https://doi.org/10.1007/s00204-012-0933-0.

5. Johnen H, Kuffner T, Brown DA, Wu BJ, Stocker R, Breit SN. Increased expression of the TGF-b superfamily cytokine MIC-1/GDF15 protects ApoE(-/-) mice from the development of atherosclerosis. Cardiovasc Pathol. 2012; 21: 499-505. https://doi.org/10.1016/j.carpath.2012.02.003.

6. Brown DA, Ward RL, Buckhaults P, Liu T, Romans KE, Hawkins NJ, Bauskin AR, Kinzler KW, Vogelstein B, Breit SN. MIC-1 serum level and genotype: associations 
with progress and prognosis of colorectal carcinoma. Clin Cancer Res. 2003; 9: 2642-50.

7. Mimeault M, Batra SK. Divergent molecular mechanisms underlying the pleiotropic functions of macrophage inhibitory cytokine-1 in cancer. J Cell Physiol. 2010; 224: 626-35. https://doi.org/10.1002/jcp.22196.

8. Roth P, Junker M, Tritschler I, Mittelbronn M, Dombrowski Y, Breit SN, Tabatabai G, Wick W, Weller M, Wischhusen J. GDF-15 contributes to proliferation and immune escape of malignant gliomas. Clin Cancer Res. 2010; 16: 3851-9. https://doi.org/1078-0432.CCR-10-0705.

9. Staff AC, Bock AJ, Becker C, Kempf T, Wollert KC, Davidson B. Growth differentiation factor-15 as a prognostic biomarker in ovarian cancer. Gynecol Oncol. 2010; 118: 237-43.

10. Welsh JB, Sapinoso LM, Kern SG, Brown DA, Liu T, Bauskin AR, Ward RL, Hawkins NJ, Quinn DI, Russell PJ, Sutherland RL, Breit SN, Moskaluk CA, et al. Large-scale delineation of secreted protein biomarkers overexpressed in cancer tissue and serum. Proc Natl Acad Sci U S A. 2003; 100: 3410-5. https://doi.org/10.1073/pnas.0530278100.

11. Emmerson PJ, Wang F, Du Y, Liu Q, Pickard RT, Gonciarz MD, Coskun T, Hamang MJ, Sindelar DK, Ballman KK, Foltz LA, Muppidi A, Alsina-Fernandez J, et al. The metabolic effects of GDF15 are mediated by the orphan receptor GFRAL. Nat Med. 2017. https://doi.org/10.1038/ nm.4393.

12. Mullican SE, Lin-Schmidt X, Chin CN, Chavez JA, Furman JL, Armstrong AA, Beck SC, South VJ, Dinh TQ, CashMason TD, Cavanaugh CR, Nelson S, Huang C, et al. GFRAL is the receptor for GDF15 and the ligand promotes weight loss in mice and nonhuman primates. Nat Med. 2017. https://doi.org/10.1038/nm.4392.

13. Yang L, Chang CC, Sun Z, Madsen D, Zhu H, Padkjaer SB, Wu X, Huang T, Hultman K, Paulsen SJ, Wang J, Bugge A, Frantzen JB, et al. GFRAL is the receptor for GDF15 and is required for the anti-obesity effects of the ligand. Nat Med. 2017. https://doi.org/10.1038/nm.4394.

14. Joshi JP, Brown NE, Griner SE, Nahta R. Growth differentiation factor 15 (GDF15)-mediated HER2 phosphorylation reduces trastuzumab sensitivity of HER2-overexpressing breast cancer cells. Biochem Pharmacol. 2011; 82: 1090-9. https://doi.org/10.1016/j. bcp.2011.07.082.

15. Li YL, Chang JT, Lee LY, Fan KH, Lu YC, Li YC, Chiang $\mathrm{CH}$, You GR, Chen HY, Cheng AJ. GDF15 contributes to radioresistance and cancer stemness of head and neck cancer by regulating cellular reactive oxygen species via a SMAD-associated signaling pathway. Oncotarget. 2017; 8: 1508-28. https://doi.org/10.18632/oncotarget.13649.

16. Sasahara A, Tominaga K, Nishimura T, Yano M, Kiyokawa E, Noguchi M, Noguchi M, Kanauchi H, Ogawa T, Minato H, Tada K, Seto Y, Tojo A, et al. An autocrine/paracrine circuit of growth differentiation factor (GDF) 15 has a role for maintenance of breast cancer stem-like cells. Oncotarget. 2017; 8:24869-24881.

17. Xu J, Kimball TR, Lorenz JN, Brown DA, Bauskin AR, Klevitsky R, Hewett TE, Breit SN, Molkentin JD. GDF15/ MIC-1 functions as a protective and antihypertrophic factor released from the myocardium in association with SMAD protein activation. Circ Res. 2006; 98: 342-50. https://doi. org/10.1161/01.RES.0000202804.84885.d0.

18. Griner SE, Joshi JP, Nahta R. Growth differentiation factor 15 stimulates rapamycin-sensitive ovarian cancer cell growth and invasion. Biochem Pharmacol. 2013; 85: 46-58. https://doi.org/10.1016/j.bcp.2012.10.007.

19. Li C, Wang J, Kong J, Tang J, Wu Y, Xu E, Zhang H, Lai M. GDF15 promotes EMT and metastasis in colorectal cancer. Oncotarget. 2016; 7: 860-72. https://doi.org/10.18632/ oncotarget.6205.

20. Chen L, Mayer JA, Krisko TI, Speers CW, Wang T, Hilsenbeck SG, Brown PH. Inhibition of the p38 kinase suppresses the proliferation of human ER-negative breast cancer cells. Cancer Res. 2009; 69: 8853-61. https://doi. org/10.1158/0008-5472.CAN-09-1636.

21. Taliaferro-Smith L, Oberlick E, Liu T, McGlothen T, Alcaide T, Tobin R, Donnelly S, Commander R, Kline E, Nagaraju GP, Havel L, Marcus A, Nahta R, et al. FAK activation is required for IGF1R-mediated regulation of EMT, migration, and invasion in mesenchymal triple negative breast cancer cells. Oncotarget. 2015; 6: 4757-72. https://doi.org/10.18632/oncotarget.3023.

22. Sanabria-Figueroa E, Donnelly SM, Foy KC, Buss MC, Castellino RC, Paplomata E, Taliaferro-Smith L, Kaumaya PT, Nahta R. Insulin-like growth factor-1 receptor signaling increases the invasive potential of human epidermal growth factor receptor 2-overexpressing breast cancer cells via Src-focal adhesion kinase and forkhead box protein M1. Mol Pharmacol. 2015; 87: 150-61. https://doi.org/10.1124/ mol.114.095380.

23. Peake BF, Nahta R. Resistance to HER2-targeted therapies: a potential role for FOXM1. Breast Cancer Manag. 2014; 3: 423-31. https://doi.org/10.2217/bmt.14.33.

24. Donnelly SM, Paplomata E, Peake BM, Sanabria E, Chen Z, Nahta R. P38 MAPK contributes to resistance and invasiveness of HER2- overexpressing breast cancer. Curr Med Chem. 2014; 21: 501-10.

25. Harner-Foreman N, Vadakekolathu J, Laversin SA, Mathieu MG, Reeder S, Pockley AG, Rees RC, Boocock DJ. A novel spontaneous model of epithelial-mesenchymal transition (EMT) using a primary prostate cancer derived cell line demonstrating distinct stem-like characteristics. Sci Rep. 2017; 7: 40633. https://doi.org/10.1038/ srep40633.

26. Lazennec G, Lam PY. Recent discoveries concerning the tumor - mesenchymal stem cell interactions. Biochim Biophys Acta. 2016; 1866: 290-9. https://doi.org/10.1016/j. bbcan.2016.10.004. 
27. Aref AR, Huang RY, Yu W, Chua KN, Sun W, Tu TY, Bai J, Sim WJ, Zervantonakis IK, Thiery JP, Kamm RD. Screening therapeutic EMT blocking agents in a threedimensional microenvironment. Integr Biol (Camb). 2013; 5: 381-9. https://doi.org/10.1039/c2ib20209c.

28. Lai W, Liu L, Zeng Y, Wu H, Xu H, Chen S, Chu Z. KCNN4 channels participate in the EMT induced by PRL-3 in colorectal cancer. Med Oncol. 2013; 30: 566. https://doi. org/10.1007/s12032-013-0566-z.

29. Senapati S, Rachagani S, Chaudhary K, Johansson SL, Singh RK, Batra SK. Overexpression of macrophage inhibitory cytokine-1 induces metastasis of human prostate cancer cells through the FAK-RhoA signaling pathway. Oncogene. 2010; 29: 1293-302. https://doi.org/10.1038/ onc.2009.420.

30. Park YJ, Lee H, Lee JH. Macrophage inhibitory cytokine-1 transactivates ErbB family receptors via the activation of
Src in SK-BR-3 human breast cancer cells. BMB Rep. 2010; 43: 91-6.

31. Wollmann W, Goodman ML, Bhat-Nakshatri P, Kishimoto H, Goulet RJ Jr, Mehrotra S, Morimiya A, Badve S, Nakshatri $\mathrm{H}$. The macrophage inhibitory cytokine integrates $\mathrm{AKT} / \mathrm{PKB}$ and MAP kinase signaling pathways in breast cancer cells. Carcinogenesis. 2005; 26: 900-7. https://doi. org/10.1093/carcin/bgi031.

32. Barbera MJ, Puig I, Dominguez D, Julien-Grille S, GuaitaEsteruelas S, Peiro S, Baulida J, Franci C, Dedhar S, Larue L, Garcia de Herreros A. Regulation of Snail transcription during epithelial to mesenchymal transition of tumor cells. Oncogene. 2004; 23: 7345-54. https://doi.org/10.1038/ sj.onc. 1207990 .

33. Derynck R, Akhurst RJ. Differentiation plasticity regulated by TGF-beta family proteins in development and disease. Nat Cell Biol. 2007; 9: 1000-4. https://doi.org/10.1038/ncb434. 